\author{
Macmillan Computer Science Series \\ Consulting Editor \\ Professor F.H. Sumner, University of Manchester
}

S.T. Allworth and R.N. Zobel, Introduction to Real-time Software Design, second edition

Ian O. Angell and Gareth Griffith, High-resolution Computer Graphics Using FORTRAN 77

Ian O. Angell and Gareth Griffith, High-resolution Computer Graphics Using

Pascal

M. Azmoodeh, Abstract Data Types and Algorithms

C. Bamford and P. Curran, Data Structures, Files and Databases

Philip Barker, Author Languages for CAL

A.N. Barrett and A.L. Mackay, Spatial Structure and the Microcomputer

R.E. Berry, B.A.E. Meekings and M.D. Soren, A Book on C, second edition

G.M. Birtwistle, Discrete Event Modelling on Simula

B.G. Blundell, C.N. Daskalakis, N.A.E. Heyes and T.P. Hopkins, An

Introductory Guide to Silvar Lisco and HILO Simulators

T.B. Boffey, Graph Theory in Operations Research

Richard Bornat, Understanding and Writing Compilers

Linda E.M. Brackenbury, Design of VLSI Systems - A Practical Introduction

J.K. Buckle, Software Configuration Management

W.D. Burnham and A.R. Hall, Prolog Programming and Applications

J.C. Cluley, Interfacing to Microprocessors

J.C. Cluley, Introduction to Low Level Programming for Microprocessors

Robert Cole, Computer Communications, second edition

Derek Coleman, A Structured Programming Approach to Data

Andrew J.T. Colin, Fundamentals of Computer Science

Andrew J.T. Colin, Programming and Problem-solving in Algol 68

S.M. Deen, Fundamentals of Data Base Systems

S.M. Deen, Principles and Practice of Database Systems

Tim Denvir, Introduction to Discrete Mathematics for Software Engineering

P.M. Dew and K.R. James, Introduction to Numerical Computation in Pascal

M.R.M. Dunsmuir and G.J. Davies, Programming the UNIX System

D. England et al., A Sun User's Guide

K.C.E. Gee, Introduction to Local Area Computer Networks

J.B. Gosling, Design of Arithmetic Units for Digital Computers

M.G. Hartley, M. Healey and P.G. Depledge, Mini and Microcomputer Systems

Roger Hutty, Z80 Assembly Language Programming for Students

Roland N. Ibbett, The Architecture of High Performance Computers

Patrick Jaulent, The 68000 - Hardware and Software

P. Jaulent, L. Baticle and P. Pillot, 68020-30 Microprocessors and their

Coprocessors

J.M. King and J.P. Pardoe, Program Design Using JSP - A Practical

Introduction

H. Kopetz, Software Reliability

E.V. Krishnamurthy, Introductory Theory of Computer Science

V.P. Lane, Security of Computer Based Information Systems

Graham Lee, From Hardware to Software - an introduction to computers

A.M. Lister, Fundamentals of Operating Systems, third edition

G.P. McKeown and V.J. Rayward-Smith, Mathematics for Computing

(continued overleaf) 
Brian Meek, Fortran, $P L / 1$ and the Algols

A. Mével and T. Guéguen, Smalltalk-80

Barry Morrell and Peter Whittle, CP/M 80 Programmer's Guide

Derrick Morris, System Programming Based on the PDP11

Y. Nishinuma and R. Espesser, UNIX - First contact

Pim Oets, MS-DOS and PC-DOS - A Practical Guide

Christian Queinnec, LISP

E.J. Redfern, Introduction to Pascal for Computational Mathematics

Gordon Reece, Microcomputer Modelling by Finite Differences

W.P. Salman, O. Tisserand and B. Toulout, FORTH

L.E. Scales, Introduction to Non-linear Optimization

Peter S. Sell, Expert Systems - A Practical Introduction

Colin J. Theaker and Graham R. Brookes, A Practical Course on Operating Systems

M.R. Tolhurst et al., Open Systems Interconnection

J.-M. Trio, 8086-8088 Architecture and Programming

M.J. Usher, Information Theory for Information Technologists

B.S. Walker, Understanding Microprocessors

Peter J.L. Wallis, Portable Programming

Colin Walls, Programming Dedicated Microprocessors

I.R. Wilson and A.M. Addyman, A Practical Introduction to Pascal-with BS6192, second edition

\section{Non-series}

Roy Anderson, Management, Information Systems and Computers

I.O. Angell, Advanced Graphics with the IBM Personal Computer

J.E. Bingham and G.W.P. Davies, A Handbook of Systems Analysis, second edition

J.E. Bingham and G.W.P. Davies, Planning for Data Communications

B.V. Cordingley and D. Chamund, Advanced BASIC Scientific Subroutines

N. Frude, A Guide to SPSS/PC+ 


\title{
Open Systems \\ Interconnection
}

\author{
Peter Boait \\ Geoff Neville \\ Ruth Norris \\ Michael Pickman \\ Mark Tolhurst (Editor) \\ John Walmsley
}

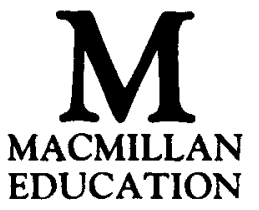


All rights reserved. No reproduction, copy or transmission of this publication may be made without written permission.

No paragraph of this publication may be reproduced, copied or transmitted save with written permission or in accordance with the provisions of the Copyright Act 1956 (as amended), or under the terms of any licence permitting limited copying issued by the Copyright Licensing Agency, 33 - 4 Alfred Place, London WC1E 7DP.

Any person who does any unauthorised act in relation to this publication may be liable to criminal prosecution and civil claims for damages.

First published 1988

\section{Published by}

\section{MACMILLAN EDUCATION LTD}

Houndmills, Basingstoke, Hampshire RG21 2XS

and London

Companies and representatives

throughout the world

British Library Cataloguing in Publication Data

Open systems interconnection.-(Macmillan

computer science series).

1. Open computer systems

I. Boait, Peter II. Tolhurst, Mark

$004.6^{\prime} 2$

ISBN 978-0-333-46803-6

ISBN 978-1-349-10306-5 (eBook)

DOI 10.1007/978-1-349-10306-5 


\section{Contents}

List of Figures $\quad$ viii

Preface $\quad$ xi

Acknowledgements xiii

1 Introduction 1

1.1 The Development of Data Communications . . . . . 1

1.2 Computer Networks . . . . . . . . . . . . . . 6

1.3 Layered Architectures . . . . . . . . . . . . . . 9

1.4 The ISO OSI Initiative . . . . . . . . . . . 11

2 Philosophy of Layered Architectures 13

2.1 Interfaces and Components . . . . . . . . . . . 14

2.2 The Network Component . . . . . . . . . . . 17

2.3 The Control Component . . . . . . . . . . . . . 21

2.4 User/Application Component . . . . . . . . . . . 22

2.5 The Philosophy . . . . . . . . . . . . . . 23

3 The OSI Model $\quad 26$

3.1 OSI Standards . . . . . . . . . . . . . . 26

3.2 Implementing OSI . . . . . . . . . . . . 28

3.3 What is Open Systems Interconnection? . . . . . . . 30

3.4 Operation within the OSI Layered Architecture . . . . 31

3.5 Formal Methods for Describing OSI Layer Operation . 44

3.6 Reference . . . . . . . . . . . . . 46

4 Physical Layer - Layer $1 \quad 47$

4.1 Requirements for Layer $1 \ldots \ldots$. . . . . . . . 50

4.2 Specification of Layer $1 \ldots \ldots \ldots$

4.3 Discussion of Technologies . . . . . . . . . . . . 55 
5 Data Link Layer - Layer $2 \quad 62$

5.1 Requirements for Layer 2 ... . . . . . . . . . 64

5.2 Specification of Layer 2 . . . . . . . . . . . . . 66

5.3 Discussion of Technologies . . . . . . . . . . 77

5.4 References................. 88

6 Network Layer - Layer $3 \quad 90$

6.1 Requirements for Layer 3 . . . . . . . . . . . . . . 94

6.2 Specification of Layer 3 . . . . . . . . . . . . . . . . . 97

6.3 Discussion of Technologies . . . . . . . . . . . 108

6.4 References..................113

7 Transport Layer - Layer $4 \quad 115$

7.1 Requirements for Layer 4 . . . . . . . . . . . 116

7.2 Specification of Layer 4 . . . . . . . . . . . . . . 118

7.3 Discussion of Technologies . . . . . . . . . . . . . . 134

7.4 References.................. 135

8 Session Layer - Layer $5 \quad 136$

8.1 Requirements for Layer 5 . . . . . . . . . . . . 138

8.2 Specification of Layer 5 . . . . . . . . . . . . . . . . 140

8.3 Discussion of Technologies . . . . . . . . . . . . 158

8.4 References.................... 159

9 Presentation Layer - Layer $6 \quad 160$

9.1 Requirements for Layer 6 ............. . 161

9.2 Specification of Layer 6 . . . . . . . . . . . . 163

9.3 Discussion of Technologies . . . . . . . . . . 176

9.4 References.................. 178

10 Application Layer - Layer $7 \quad 179$

10.1 Requirements for Layer 7 . . . . . . . . . . . 180

10.2 Specification of Layer 7 . . . . . . . . . . . . . . 181

10.3 Discussion of Technologies . . . . . . . . . . . . 196

10.4 References . . . . . . . . . . . . . . 197

11 Applications of OSI 199

11.1 Technical Limitations . . . . . . . . . . . . . . . . 199

11.2 Limitations by Omission . . . . . . . . . . . 201 
11.3 Political Limitations . . . . . . . . . . . . . . 202

11.4 Natural Applications of OSI . . . . . . . . . . 203

11.5 X.400 Message Handling Systems . . . . . . . . . . 206

11.6 The Future of OSI . . . . . . . . . . . . . . . 209

11.7 Reference . . . . . . . . . . . . . . 210

$\begin{array}{ll}\text { Definition of OSI Terms } & 211\end{array}$

$\begin{array}{ll}\text { Glossary } & 214\end{array}$

$\begin{array}{ll}\text { Index } & \mathbf{2 1 7}\end{array}$ 


\section{List of Figures}

1.1 A point-to-point link . . . . . . . . . . . 2

1.2 A simple circuit switch . . . . . . . . . . . . 3

1.3 A patch panel . . . . . . . . . . . . . 4

1.4 Multiplexed terminals . . . . . . . . . . . . 4

1.5 The use of modems . . . . . . . . . . . . . . 5

1.6 A typical computer network . . . . . . . . . . 8

1.7 A layered architecture . . . . . . . . . . . 11

2.1 A hypothetical communications architecture . . . . . 17

2.2 A communications network . . . . . . . . . 20

2.3 The seven layers of the OSI model . . . . . . . . . 24

2.4 Diagrammatic representation of the OSI model . . . . . 25

3.1 Partial implementations of OSI . . . . . . . . . . . 29

3.2 Open systems . . . . . . . . . . . . . . . . 31

3.3 High level view of open systems interconnection . . . . . 32

3.4 Communication between subsystems ......... 33

$3.5(\mathrm{~N})$-subsystems and $(\mathrm{N})$-layers $\ldots \ldots \ldots \ldots$

3.6 The $(\mathrm{N})$-connection . . . . . . . . . . . . . 35

3.7 Establishing a connection between application entities . . 36

3.8 Intermediate open systems . . . . . . . . . . . 37

3.9 Entities connected via service access points . . . . . 38

3.10 PDUs and IDUs . . . . . . . . . . . . . . 39

3.11 Data units and their relationship . . . . . . . . . 40

3.12 Blocking and deblocking . . . . . . . . . . 41

3.13 Segmenting and reassembling ........... 41

3.14 Concatenation and separation . . . . . . . . . . 42

3.15 Multiplexing and splitting . . . . . . . . . . 43

3.16 Exchange of primitives to provide a confirmed service . . 44

3.17 Time sequences of primitives . . . . . . . . 45

3.18 Finite state machine . . . . . . . . . . . . . 46

4.1 A bus topology . . . . . . . . . . . . . 48 
4.2 Multipoint topology with master and slave stations . . . 48

4.3 A ring topology . . . . . . . . . . . . . . . 49

4.4 Examples of V.24 parallel circuits . . . . . . . . . 51

4.5 Activating a physical connection . . . . . . . . 53

4.6 Connectionless data transfer . . . . . . . . . . . . 54

4.7 Real physical connections . . . . . . . . . . . 55

4.8 CSMA/CD sublayers in relation to the OSl model . . . 58

5.1 Connection-oriented Data Link Layer primitives . . . . 68

5.2 Connection-oriented transfer of data . . . . . . . . . 69

5.3 Unbalanced data link configuration . . . . . . . . . 71

5.4 Balanced data link configuration . . . . . . . . 72

5.5 Symmetrical data link configuration . . . . . . . 73

5.6 HDLC frame format . . . . . . . . . . 78

5.7 HDLC control fields . . . . . . . . . . . . . . 80

5.8 S Frame commands and responses . . . . . . . . . 82

5.9 Unnumbered command frames . . . . . . . . . . 83

5.10 Unnumbered responses . . . . . . . . . . . . . . . . 84

5.11 Fundamental repertoires of HDLC classes of procedure . . 85

5.12 IEEE 802 inter-relationships . . . . . . . . . . . . . 86

5.13 LLC to MAC sublayer primitives . . . . . . . . . . . 87

5.14 Relationship between LLC PDU and MAC frame . . . . . 88

6.1 A subnetwork with many routes between nodes . . . . . 92

6.2 Connection using a single network protocol . . . . . . 96

6.3 Connection using multiple protocols . . . . . . . . . . 97

6.4 Structure of an NSAP address . . . . . . . . . . 99

6.5 Network connection modelled as a pair of queues . . . . 100

6.6 Summary of Network Layer primitives . . . . . . . . . . 101

6.7 Network Connection Establishment service . . . . . . . 103

6.8 Reset service invoked by network service user . . . . . . 105

6.9 Network Connection Release service . . . . . . . . . 107

6.10 General X.25 packet format . . . . . . . . . . . . . 109

6.11 X.25 packet types . . . . . . . . . . . 110

6.12 Primitive to packet mapping . . . . . . . . 113

7.1 Procedure classes and network connection types . . . . . 120

7.2 Transport connection modelled as a pair of queues . . . 124

7.3 Summary of Transport Layer primitives . . . . . . . 125 
7.4 General TPDU format . . . . . . . . . . . 126

7.5 TPDU formats . . . . . . . . . . . . . 127

7.6 Two-way connection establishment . . . . . . . 130

7.7 Data Transfer service . . . . . . . . . . . . . 131

7.8 Implicit disconnection . . . . . . . . . . . . . 132

7.9 Explicit disconnection . . . . . . . . . . . 133

8.1 General SPDU format . . . . . . . . . . . . 143

8.2 Parameter field with single parameter . . . . . . . 144

8.3 Parameter field with parameter group . . . . . . . . 144

8.4 Relationship between services, functional units and subsets . . . . . . . . . . . . . . . 146

8.5 Session Layer functional units and related services . . . 148

8.6 Establishing a session connection . . . . . . . . . 150

8.7 Normal Data Transfer service . . . . . . . . . . . 151

8.8 Orderly Release service . . . . . . . . . . . . . 152

8.9 User-Initiated Abort service . . . . . . . . . . . . . 153

8.10 Provider-Initiated Abort service . . . . . . . . . 155

8.11 Summary of Session Layer primitives . . . . . . . 156

8.12 Give Control service . . . . . . . . . . . . . 157

9.1 Establishing a presentation connection . . . . . . . 169

9.2 Normal Data Transfer service . . . . . . . . . . . . 170

9.3 Alter Context service . . . . . . . . . . . . . . . 172

9.4 Connection Release service . . . . . . . . . . 173

9.5 User Abort service . . . . . . . . . . . . . . . . . . . 174

9.6 Provider Abort service . . . . . . . . . . . . . 176

9.7 Summary of Presentation Layer primitives . . . . . . 177

10.1 Application entity . . . . . . . . . . . 182

10.2 A-ASSOCIATE/P-CONNECT mapping . . . . . . . 184

10.3 Virtual terminal . . . . . . . . . . . . . 187

10.4 Virtual filestore . . . . . . . . . . . . . . . 190

10.5 FADUs and DUs . . . . . . . . . . . . . . 191

10.6 Work specification . . . . . . . . . . . . . . 193

10.7 System management . . . . . . . . . . . . . . 195

11.1 MAP 3.0 protocol stack . . . . . . . . . . . . 205

11.2 The X.400 message handling system model . . . . . 208 


\section{Preface}

Information is increasingly recognised as a commodity whose value rises in proportion to its portability. From financial institutions operating in markets across the world to car makers running automated production lines, many businesses depend upon the immediate and reliable transfer of information from one computer system to another.

In a market-place bedevilled by the incompatibility of so many of the products on sale, this apparently straightforward requirement has proved extremely difficult to satisfy. Although individual manufacturers have provided proprietary solutions, these have not proved adequate to achieve the ultimate goal - full compatibility in communication between computer systems.

In common with similar moves in other areas of information technology, the International Organization for Standardization (ISO) has therefore overseen the production of a model for open systems interconnection (OSI) - that is, the facility for one OSI-compliant system to be able to interact with any other OSI-compliant system. The intention is that the OSI model and its associated standards will be universally accepted as the framework for the future development of inter-system communications.

From the evidence of the growing number of OSI-compliant products being released, OSI appears to have been a decisive and necessary initiative. There seems every prospect that the pattern of data communications in the future will be shaped by OSI: not only does OSI meet the current need for regulation in a previously unregulated area, but it also provides sufficient flexibility to incorporate the inevitable advances which will be made in the swiftly evolving field of communications technology.

This book aims to give a general introduction to OSI for engineers, students and others who need to become familiar with its concepts and terminology. The two opening chapters give an histori- 
cal account of the development of data communications and describe the philosophy of layered architectures. In Chapter 3, the principles of the seven layer OSI model are explained and OSI terminology is introduced.

Each of the seven chapters which follow deals with a layer of the OSI model. The reader with a general interest in OSI is directed to the introduction and the 'requirements' section of each chapter, which give an overview of the layer in question and its functions in relation both to the model and to the data communications environment. The 'specification' section describes in detail how the layer operates to fulfil its requirements. Each chapter concludes with a discussion of the current communications technologies, if any, which comply with the OSI standards for the layer.

The final chapter reviews the present state of OSI development. It makes particular reference to the X.400 message handling system, currently the most widely available OSI-compliant implementation.

Chapter references include the relevant OSI standards and drafts for development, as published by the British Standards Institution; the equivalent ISO references are also given.

The emphasis in the current OSI standards is on connectionoriented communication between computer systems. Connectionless services are on the whole described in addenda to those standards which define the connection-oriented services, although the intention is that these addenda should be incorporated in the main body of standards as soon as possible. This book reflects the present state of OSI development and treats connection-oriented layer services as being of primary importance. 


\section{Acknowledgements}

The authors, who are all employees of Admiral Computing Group plc, wish to thank Dr Ceri James, Managing Director of the company, for making available Admiral's resources, without which this book would not have been produced. We would have made slow progress without the help and support of our colleagues in Bristol - in particular, Peter Craig, Steve Lloyd and Martin Millener who contributed in various and significant ways to the content and appearance of the finished book. Special thanks are due to Julie Knight and Nigel Murkitt for their work on the word processing and typesetting of the book.

In addition, we should like to acknowledge the assistance and information we received from Digital Equipment Corporation (DEC), ICL and Tandem Computers Limited, computer manufacturers who are currently marketing OSI-compliant products. 